\title{
Construction Strategic Project Readiness Assessment
}

\author{
Mahdi Safa ${ }^{1}$, Kelly Weeks ${ }^{2}$, Ashraf ELHoubi ${ }^{3}$, Nomita Sharma ${ }^{4}$, and Sandra MacGillivray ${ }^{5}$ \\ ${ }^{1}$ Senior Lecturer, Department of Civil and Environmental Engineering, University of Houston, Houston, TX 77004, U.S., \\ E-mail: msmahdisafa@gmail.com (corresponding author). \\ ${ }^{2}$ Associate Professor, College of Business, Lamar University, Beaumont, TX 77710, U.S. \\ ${ }^{3}$ Professor, College of Business, Lamar University, Beaumont, TX 77710, U.S. \\ ${ }^{4}$ Assistant Professor, Department of Management, University of Delhi, 75/2, Ram Nagar Extension, Delhi, India \\ ${ }^{5} \mathrm{CEO}$, Valency Inc., St, Suite 1, Waterloo, ON N2V 2B3, Canada \\ Project Management
}

Received December 26, 2020; revised April 15, 2021; May 23, 2021; accepted June 5, 2021

Available online July 1, 2021

\begin{abstract}
Proper use of construction strategic management consists of strategic planning for controlling the implementation of strategies during front-end planning (FEP). To improve FEP effort, industry best practice instrument, i.e., Project Definition Rating Index (PDRI) has been used to ensure continued alignment and focus on strategic project priorities. This study proposes a methodology for creating a SWOT (strengths, weaknesses, opportunities, and threats) analysis of big post-mining data from organizations that have implemented PDRI, as a standardized tool used across capital project portfolios. The results show that the proposed methodology has the potential to improve project success when applied as a benchmark of baseline conditions, the element level.
\end{abstract}

Keywords: Project management; knowledge management; information technology, construction.

Copyright @ Journal of Engineering, Project, and Production Management (EPPM-Journal).

DOI 10.32738/JEPPM-2022-0002

\section{Introduction}

Through evolving research, the 21 st century has witnessed outstanding achievements in different areas of project management and science such as governance, strategic management, technology management, sustainability, innovation, supply chain management and procurement, organizational learning, crisis management, institutional theory, concurrent engineering, knowledge and information management, complexity, culture, ethics (Gerwin and Susman, 1996; Miller and Hobbs 2005; Cox and Ireland, 2006; Bresnen, 2007; Morris, 2013; PMI, 2013; Gemünden, 2015; Rolfe et al., 2016). This evolution proved particularly valuable with regards to construction project management (Helm and Remington, 2005; Eastman et al., 2011; Shokri et al., 2011; Safa, 2013; Shahi et al., 2014; Walker, 2015; Zheng et al., 2016). A construction project can be described as a combination of many events and interactions, processes in a constantly changing environment, and a sequential action that relies profoundly on detailed planning (Safa et al., 2013; Banihashemi et al., 2017). Capital construction projects produce an enormous quantity of data in all the phases of project lifecycles (Safa et al., 2015b). Ordinarily, databases storing these large data sets (big data) form a historical record, accumulated over the different phases of largescale projects. When analyzed, these databases can also serve as a worthy asset for evaluation of the performance of project and planning. However, the intricate, and amorphous nature of the rapidly generated data, collected over the project duration, prohibits traditional data management techniques such as data visualization and relational databases. This challenge necessitates substantial research in the evolution of the vigorous big data analytics technique for construction projects. This study concentrates on the analysis of massive amounts of FEP data from organizations that have implemented the PDRI for SWOT analysis.

The project management paradigm and its processes have been comprehensively defined through general bodies such as the Project Management Institute and Construction Industry Institute (CII) (PMI, 2008). One of the most important and valuable processes in the construction capital project life cycle is FEP. FEP is a systematic process, which defines the approach to ensure the objectives of construction projects are accomplished. This process provides sufficient documentation to support owners and investors in addressing project risks, and in making resource-allocation decisions to maximize the probability of project success. During the FEP phase of construction capital projects, long-term strategies are formed based on project constraints. Resource limitations, government regulations, and environmental restrictions are just a few examples of these constraints (Gibson, 2005; 
Safa et al., 2015a). It is challenging to acquire an extensive comprehension of such perils throughout the FEP phase.

Construction projects are from an industry in which uncertainty is more common than in most others. Circumstances are unpredictable with no historical records or references describing the condition that is being analyzed. Aside from all the possible negative impacts of construction upon the environment, the sheer uniqueness of each project is an underlying source of uncertainty. Considering the participation of private financiers, conditions of the financial market, and the economy in general, maintaining the schedule of construction within budget is very important (Kerzner, 2018). Project failure often befalls due to not paying enough attention to difficulties in the projects, including the operational problems (Allport et al., 2008). It would be far simpler to manage expenses, schedules, and quality if problems were predictable and thus avoidable. Projects that are large and complex or new, will have a higher possibility of higher risk. It hints that though the price of risk is high, the price of mishandling the risk is even higher.

Critically evaluating projects' progress, strengths, and limitations will help the project managers to prioritize. In recent years, the construction environment has become risky, and many construction projects have proven to be unsuccessful (Luu et al., 2008; Ezeldin and Sharara, 2006). There is a significant risk with respect to cost and schedule development (dos Santos and Jungles, 2016; Koulinas et al., 2020) in the case of large capital projects. These projects could be related to oil sands and pipelines. Due to the large, complex data sets collected during FEP, big data analytics can ameliorate planning and decision-making effectiveness and efficiency. This is done by providing insights that highlight the most feasible alternatives and allow tasks within a portfolio of projects to be prioritized; it can help minimize overall project delivery risks and can enable project performance appraisals for prediction or review purposes. Hence, a methodology has been developed to address risks and evaluate the status of a project during the FEP phase. The purpose of the paper is to implement a systematic SWOT analysis by utilizing the method, PDRI methodology output. The developed methodology concentrates on the available success parameters or those to be developed during the planning period.

The benefits of the strategic implementation of FEP practices, during the entire project, have turned the spotlight on FEP evaluation for both academicians and project leaders. Recent construction research has been directed at the establishment of a common set of construction phase metrics and their corresponding definitions (Park et al., 2005; Rankin et al., 2008; Willis and Rankin, 2012; Oppong et al., 2017). Large capital construction projects are fraught with significant planning issues, with cost and scheduling remaining key areas of scrutiny. Failure to exploit opportunities for improving project value and decreasing risks during the FEP phase could lead to the undervaluation of such projects (Machiels et al., 2021). As mentioned, acquiring an in-depth understanding of this type of risk is challenging because neither spending nor delivery has begun during this phase. Hence, one of the major assignments during the FEP phase for mitigating risk is the sufficient progress of the welldefined scope of the project (Ward, 1995; Collins and Baccarani, 2004). Project scope definition involves a critical process. All the risks are analyzed at this critical stage of the project and a well-defined approach for execution. The extent of the effort in designing the detailed construction plan, and the initial scope definition of a project, decide the project's success (Cho and Gibson, 2001). These scopes are usually defined and developed by the highest level of the project management team members and involve long-range commitment and a large investment of resources. The appraisal of project scope can circumvent the problems and develop a problem-centered successful project. Working through a comprehensive analysis methodology in the project's initial planning phase is an excellent practice to employ. Hence, a strategic project readiness assessment has been created to furnish a more objective interpretation of the level of scope definition and to shape an effective project pre-planning progress monitoring. The primary objective of the study is to highlight the tools for a unified evaluation methodology. Different techniques and management tools have been used in developing the proposed methodology, including SWOT and PDRI. The sections that follow, SWOT and PDRI, provide a brief exploration and synopsis of the academic work whose contributions have been referred by the research presented in this study.

\subsection{SWOT (Strengths, Weaknesses, Opportunities, and Threats)}

The success of the project is an abstract concept, which can be determined through performance measures during FEP and another phase of a project (Chan et al., 2002). Hence, construction managers need to evaluate the status of the project, particularly during strategic planning, and then compare this with their past performance in order to find out what should be improved (Gupta, 2004). Strategic planning has its mutual origin in the work of business policy academics at American business schools, in particular, Harvard Business School, from the 1960s onward (Hill and Westbrook, 1997). SWOT analysis has become one of the most important and popular supporting tools for strategic planning (Lu, 2010; Stewart et al., 2002; Yüksel and Dagdeviren, 2007; Teixeira and Cordeiro, 2017). The SWOT analysis technique is adopted as a systematic framework promoting understanding of the internal and external status and provisions of a construction project (Lu et al., 2013). In this study, similar to many other cases, SWOT can be applied along with other audit and analysis tools in the current projects (Zavadskas et al., 2011). SWOT has not been outdated with the fast development of management science, because, it is inclusive and fits alongside other methodologies and approaches. For instance, a SWOT analysis can comprehensively include a number of different forms of such as scenario analysis, Porter's five forces model, and resource-based approaches (David et al., 2017). While somewhat simple to understand, a SWOT is flexible enough to be used by various types of organizations and companies ( $\mathrm{Lu}, 2010)$. The concept of SWOT is derived from the area of business management and it has been extensively used in a wide range of other streams, including construction management. Table 1 shows the results of a SWOT analysis and the present status of waste management in Shenzhen city in south China (Yuan, 2013). 
Table 1. Sample of a project SWOT analysis for the waste management

\begin{tabular}{ll}
\hline \multicolumn{1}{c}{ Internal Conditions } & \multicolumn{1}{c}{ External Conditions } \\
\hline Strengths & Opportunities \\
\hline Regional location; & $\begin{array}{l}\text { Special status due to } \\
\text { special economic zone } \\
\text { (SEZ) scheme; }\end{array}$ \\
\hline $\begin{array}{l}\text { Higher awareness of local } \\
\text { authorities regarding } \\
\text { promoting waste } \\
\text { management in the } \\
\text { construction sector; }\end{array}$ & $\begin{array}{l}\text { Focus on construction } \\
\text { waste reduction; }\end{array}$ \\
\hline $\begin{array}{l}\text { The main part in initiating } \\
\text { waste management-related } \\
\text { regulations. }\end{array}$ & $\begin{array}{l}\text { Major support from the } \\
\text { public and private } \\
\text { Weaknesses }\end{array}$ \\
\hline $\begin{array}{l}\text { Insufficient regulations for } \\
\text { waste management in the } \\
\text { construction sector; }\end{array}$ & \begin{tabular}{l} 
Inadequate landfill sites; \\
\hline $\begin{array}{l}\text { Less on-site sorting of } \\
\text { waste; }\end{array}$
\end{tabular} \\
\hline $\begin{array}{l}\text { Substandard reduction of } \\
\text { waste; }\end{array}$ & $\begin{array}{l}\text { Less monetary fine for } \\
\text { land-filling; }\end{array}$ \\
\hline $\begin{array}{l}\text { Absence of integral } \\
\text { planning for recycling } \\
\text { facilities for construction } \\
\text { waste. }\end{array}$ & $\begin{array}{l}\text { for recycling of } \\
\text { construction waste; }\end{array}$ \\
\hline
\end{tabular}

To successfully operate and manage large construction projects, the management team needs to concentrate on future objectives on the strengths of the company, while averting tendencies related to the potential weaknesses. The other strategic planning tool employed in this research, PDRI, is a proven, leading indicator of risk. In current use as a widely adopted FEP standard, the PDRI stipulates key project elements suitable for representing the project team's own assignment of scope definition ratings. The PDRI provides a framework for these ratings that allows project stakeholders to contribute expertise and helps them acquire an understanding of the cross-functional impact of any risks identified. Functioning as a multifaceted frontend planning tool, PDRI operates as a vehicle for the facilitation of strategic decision-making through the evaluation of scope readiness as a means of measuring project risk. PDRI's are tailored to adhere to the particular requirements of the building, industrial, and infrastructure sectors of the construction industry (Weerasinghe et al., 2007; Gibson et al., 2010; Weeks et al., 2020).

\subsection{Project Definition Rating Index (PDRI)}

Project management teams, especially those working in organizations with interoperability challenges can deploy management tools along with best practices as a significant means for improving project management processes (Lee et al., 2015; Eskerod et al., 2015; Serrador and Turner, 2015; Turner and Zolin, 2012). The understanding of project strategic planning and FEP in regard to optimism bias and strategic misrepresentation are the main factors (low definition factors) that need to be considered in construction megaprojects (Flyvberg, 2014; Sutterfield et al., 2006). Insufficient definition of the project scope is acknowledged as one of the main reasons for the failure of the project (Mirza et al., 2013). It can also result in overexpenditure, miss deadlines, or even have operational issues in the long term. Thus, FEP is one of the most imperative techniques for construction projects.

The primary output of the FEP phase is the perfect design that can help in cost and schedule estimates and make strategic decisions to identify risk (Gibson et al., 2006; Safa et al., 2014; Johnson et al., 2021). Once the financial requirements of the project are approved, the output of the FEP design becomes the main input for the subsequent phases in the life cycle of the project. The FEP check-points, four PDRI potential application points, along other phases of the life cycle of the project are illustrated in Fig. 1. A gate or check-point is defined as the presence of unique information regarding definitions essential for a decision to proceed or not.

The CII offers a great setting of PDRI and a proven project risk review methodology based entirely on an assessment of the complete scope definition of the main elements of the project. The PDRI that the CII team created for construction projects includes an extensive checklist of about 70 elements explaining scope definition. It has three important sections based on the project decision, design, and approach of execution (Fig. 2). The list of the elements was categorized through an extensive assessment of the best industry practices and was given weightage as per importance indicated by more than 50 skilled project managers and proficient estimators (CII, 2010).

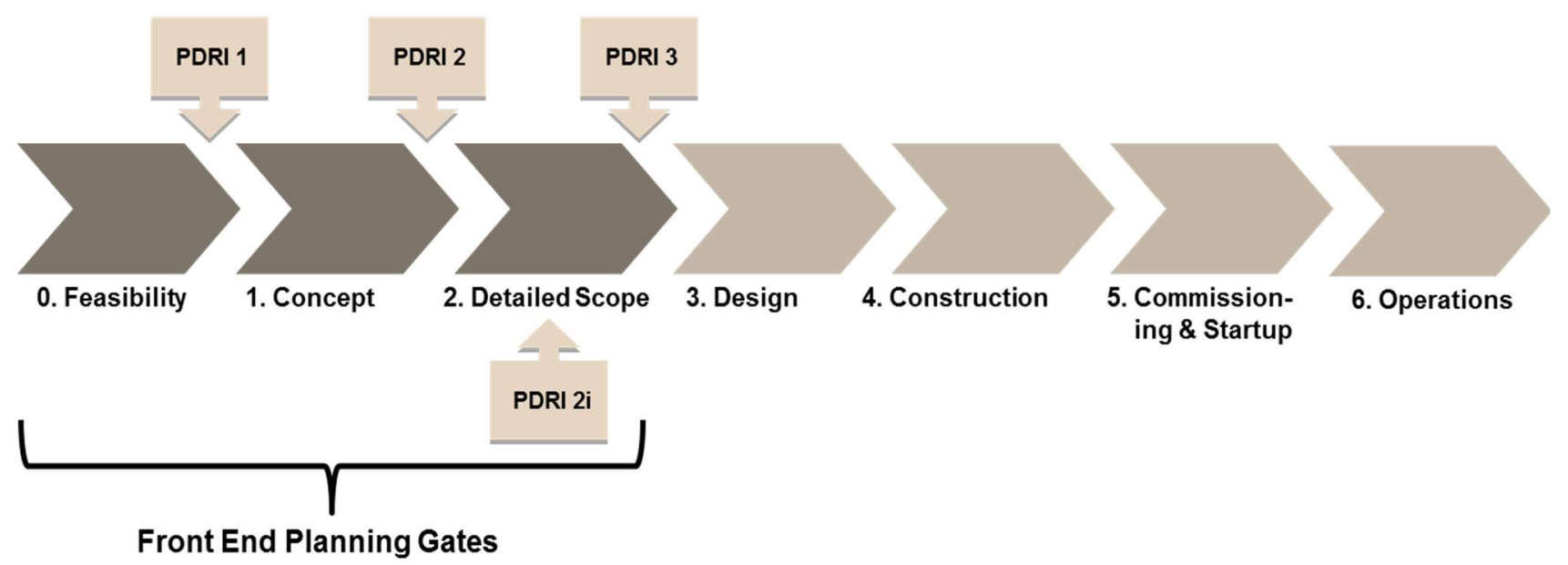

Fig. 1. Front-end planning gates and potential PDRI application points 
The process drills down to the essential details so that stakeholders can contribute critical components and realize the impact of the risks across the different functional areas. This tool allows both, an individual or a team to assess project status during FEP. It also develops a scorespecifying level of definition. Empirical evidence has shown that the PDRI can result in $6 \%$ to $25 \%$ savings in the overall cost of a project (CII, 2010).

All PDRIs provide high-level project assessments following designated FEP phases. Fig. 2 indicates the points where PDRIs are recommended. PDRI 1 follows the FEP feasibility phase and entails a very important evaluation of the project, which is usually taking place in the initial project meeting with an architectural/engineering firm. The PDRI 2 review involves a critical evaluation of the project. This is followed by the concept development phase that has the goals of evaluating the association of objectives of the project with the requirements of stakeholders by recognizing the high-priority-based output of the projects.
It can help in predicting unforeseen situations in the project and also facilitate a dialogue among the project team and stakeholders. PDRI 2, section I, is a mid-way evaluation of the project, which is held at the midpoint of the detailed scope phase of the FEP. Its purpose is to associate project objectives with stakeholder needs and confirm the structured disposal of resources, verify that the scope corresponds to the goals of the project, and identify and plan any other essential activities for the next phase of FEP. PDRI 3 is the final evaluation of the project where risk issues have been identified, and alleviation plans have been developed. The overall maximum score to quantify according to the level of scope definition for all the stages of the FEP (feasibility, concept, and detailed scope) is a 1000 -point scale. If a project management team, based on the nature of the project, decides to scale down the PDRI by eliminating some elements, the maximum possible score would be lower than 1000 points. In other words, any eliminated element from the checklist reduces the total scores. Fig. 4 shows the excerpt of two categories and their elements.

\section{BASIS OF PROJECT DECISION}

A. Manufacturing Objectives Criteria Al. Reliability Philosophy

A2. Maintenance Philosophy

A3. Operating Philosophy

B. Business Objectives

B1. Products

B2. Market Strategy

B3. Project Strategy

B4. Affordability / Feasibility

B5. Capacities

B6. Future Expansion Considerations

B7. Expected Project Life Cycle

B8. Social Issues

C. Basic Data Research \& Development

C1. Technology

C2. Processes

D. Project Scope

D1. Project Objectives Statement

D2. Project Design Criteria

D3. Site Chars. Available vs. Required

D4. Dismantling \& Demolition Req'mts

D5. Lead / Discipline Scope of Work

D6. Project Schedule

E. Value Engineering

E1. Process Simplification

E2. Design \& Material Alternatives Considered / Rejected

E3. Design For Constructability Analysis

\section{FRONT END DEFINITION}

\section{F. Site Information}

F1. Site Location

F2. Surveys \& Soil Tests

F3. Environmental Assessment

F4. Permit Requirements

F5. Utility Sources with Supply Conds.

F6. Fire Prot. \& Safety Considerations

G. Process / Mechanical

G1. Process Flow Sheets

G2. Heat \& Material Balances

G3. Piping \& Instrmt. Diags. (P\&ID's)

G4. Process Safety Mgmt. (PSM)

G5. Utility Flow Diagrams

G6. Specifications

G7. Piping System Requirements

G8. Plot Plan
G9. Mechanical Equipment List

G10. Line List

G11. Tie-in List

G12. Piping Specialty Items List

G13. Instrument Index

H. Equipment Scope

H1. Equipment Status

H2. Equipment Location Drawing

H3. Equipment Utility Requirements

I. Civil, Structural, \& Architectural

I1. Civil / Structural Requirements

I2. Architectural Requirements

J. Infrastructure

J1. Water Treatment Requirements

J2. Loading / Unloading / Storage Facilities Requirements

J3. Transportation Requirements

K. Instrument \& Electrical

K1. Control Philosophy

K2. Logic Diagrams

K3. Electrical Area Classifications

K4. Substation Requirements / Power Sources Identified

K5. Electric Single Line Diagrams

K6. Instrument \& Electrical Specs.

\section{EXECUTION APPROACH}

L. Procurement Strategy

L1. Identify Long Lead / Critical Equipment \& Materials

L2. Procurement Procedures \& Plans

L3. Procurement Resp. Matrix

M. Deliverables

M1. CADD / Model Requirements

M2. Deliverables Defined

M3. Distribution Matrix

N. Project Control

N1. Project Control Requirements

N2. Project Accounting Req'mts

N3. Risk Analysis

P. Project Execution Plan

P1. Owner Approval Requirements

P2. Engr. / Constr. Plan \& Approach

P3. Shut Down/Turn-Around Req'mts

P4. Pre-Commissioning Turnover

Sequence Requirements

P5. Startup Requirements

P6. Training Requirements

Fig. 2. PDRI elements and sections (Gibson and Dumont, 2004) 


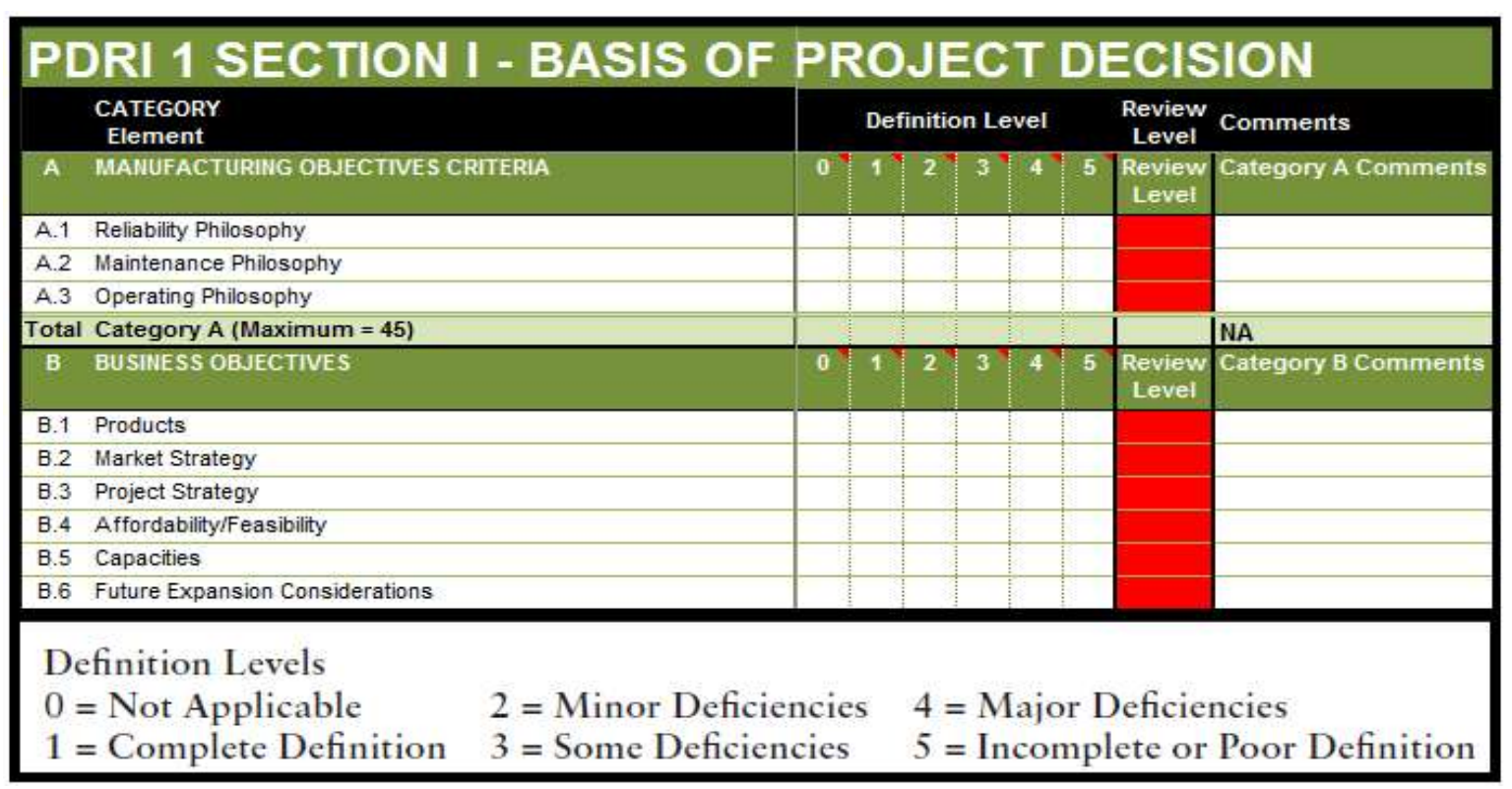

Fig. 3. Example of categories and elements

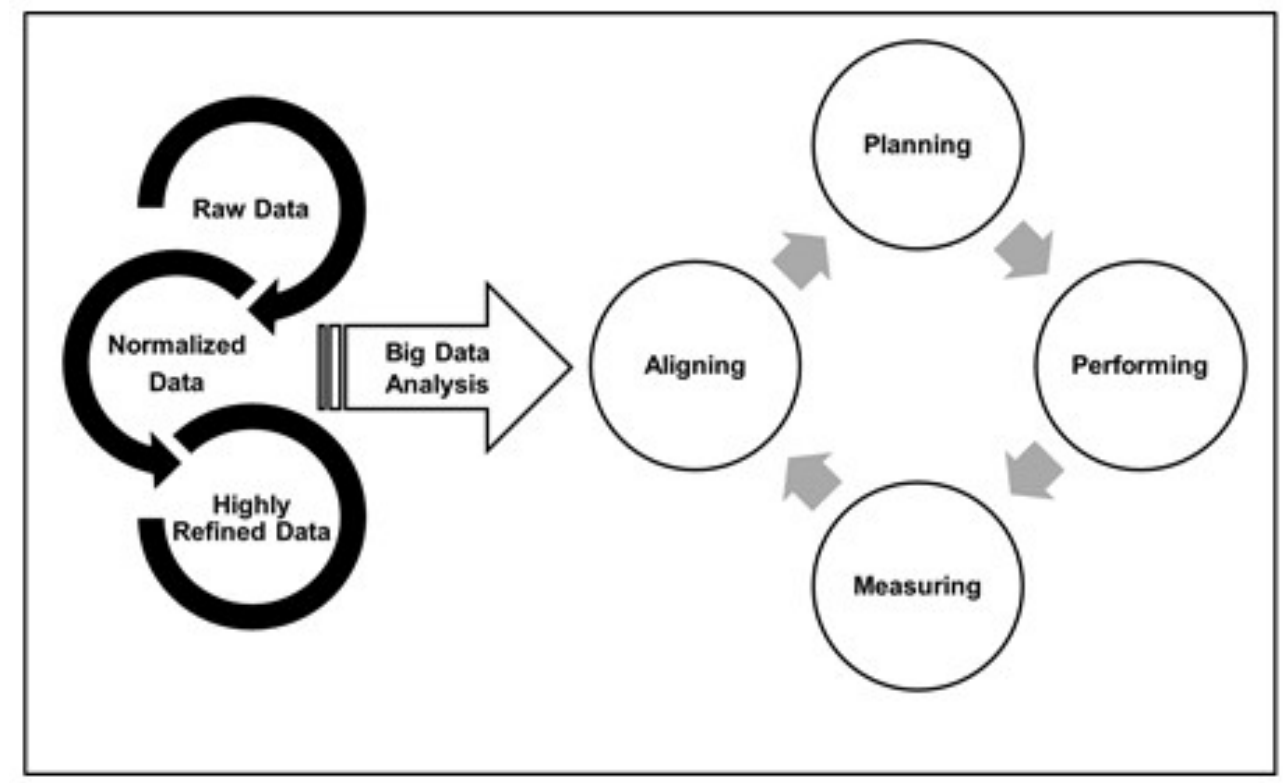

Fig. 4. General data analysis environment for PDRI data

In general, the usual scores at the completion of this assessment are between 150 and 250. The preferred score is 200 or less. The PDRI score ranges that are allowed for individual FEP phases are summarized in Table 2 (Gibson et al., 2010). The suggested procedure is for all PDRIs to be conducted for all projects. However, if for any reason, the project management team is unable to implement all PDRIs, as a minimum, PDRI 3 should be completed in order to identify risk issues.

Due to the complex and large data sets collected during FEP, big data analytics can refine planning effectiveness and efficiency for better decision-making. It can provide insights that highlight the most feasible alternatives while allowing tasks within a portfolio of projects to be prioritized; thus, it can help minimize overall project delivery risks and can enable project performance appraisals for prediction or review purposes. Fig. 4 shows the general data analysis environment for PDRI data. It shows the key analysis processes and how the results can be applied for improving the FEP.
Table 2. Acceptable PDRI scores (CII, 2010)

\begin{tabular}{ccccc}
\hline Stage & $\begin{array}{c}\text { PDRI 1: } \\
\text { Feasibility }\end{array}$ & $\begin{array}{c}\text { PDRI 2: } \\
\text { Concept }\end{array}$ & $\begin{array}{c}\text { PDRI 2i: } \\
\text { Detailed } \\
\text { Scope }\end{array}$ & $\begin{array}{c}\text { PDRI 3: } \\
\text { Detailed } \\
\text { Scope }\end{array}$ \\
\hline $\begin{array}{c}\text { Typical } \\
\text { Min } \\
\text { Typical } \\
\text { Max }\end{array}$ & 550 & 450 & 300 & 150 \\
\hline
\end{tabular}

To apply big data analytics in the FEP phase of projects, a robust data collection system must be designed as per the nature of the project and the purpose of the analysis. This system should output both newly collected and historical data to an assessment standard for analysis.

The association between a PDRI and risk factors related to the performance of the project is on the basis of analysis of the data published from hundreds of the projects. There is a chance now to employ historical project data sets at a portfolio level as a means of mining the 
powerful constituent elements of the index in order to develop methods that can support construction firms as they form proactive planning strategies for the execution of each new capital project. There is never a lack of demands for portfolio managers to contend with when overseeing multiple projects (e.g., in terms of resource, cost, and schedule management). PDRI big data analysis has the potential to deliver the necessary intelligence and level of detail to ease and enhance a portfolio manager's decision-making process. With PDRI big data analysis, portfolio managers can have a more informed judgment of which portfolio features require greater priority. By having exhaustive information about FEP during portfolio design and management, the value of the portfolio can be maximized. A sample of the types of analyses that can be applied to historical PDRI data includes FEP elements influencing the performance of the project; leading indicators for forecasting performance of the project in terms of over-expenditure and time overrun; insights into project status using key performance indicators; projects classification based on major associated risks; and understanding FEP issues (low scored elements). These deliverables can also support continuous improvement in the FEP phase. While considerable attention has been paid to the PDRI methodology, the big data analysis of historical FEP data sheds some light on a more promising avenue for changes and improvements, notably in the FEP phase.

\section{Research Methodology}

Capital construction projects deal with voluminous data throughout the different stages of the project lifecycles. Ordinarily, databases storing these large data sets (big data) form a historical record, accumulated over the different phases of large-scale projects. These databases are a useful resource for planning and evaluating the performance of a project. However, the complicated and unorganized nature of the fast generated data, collected over the duration of a capital project, does not permit the use of relational databases and data visualization, which are termed traditional data management methods. Such a barrier necessitates substantial research in the evolution of strong big data analytics techniques for projects in the construction sector. As mentioned, FEP is the concept of generating enough documentation to support owners and investors in addressing project risks, and in making resource-allocation decisions to augment the probability of success of the project. During the FEP phase, long-term strategies are formed based on project constraints. Resource limitations, government regulations, and environmental restrictions are just a few examples of these constraints.

As a widely adopted FEP standard, the PDRI facilities project appraisal by stipulating key project elements, which are rated by stakeholders in terms of scope definition. The PDRI scoring framework enables the project team to pool their expertise in a workshop format to identify and understand the cross-functional impact of project risks. Big data analytics creates the opportunity to mine historical PDRI data for constituent elements. More robust methods can be developed based on these insights to support capital project organizations in proactive strategic planning. Such methods include the implementation of specific processes, information technology systems, and training to fill existing capability and knowledge gaps that are common within the construction industry.

As a part of the strategic planning process, various companies conduct SWOT analyses in order to recognize the strengths, weaknesses, opportunities, and threats, associated with a specific project. After selecting the SWOT analysis, the knowledge-based methodology is emerging with the acquisition of knowledge from PDRI evaluation. Knowledge acquisition can be defined as the process of extracting knowledge from different sources and then modeling it. The term knowledge refers to awareness about different aspects of the project (e.g., facts, culture, heuristic rules, and relationships) with familiarity gained through experience and other sources. In order to conduct SWOT analyses, a framework is prepared by identifying the strength and weakness factors (internal factors) and the opportunity and threat factors (external factors). The following, Fig. 5, shows the developed methodology steps.

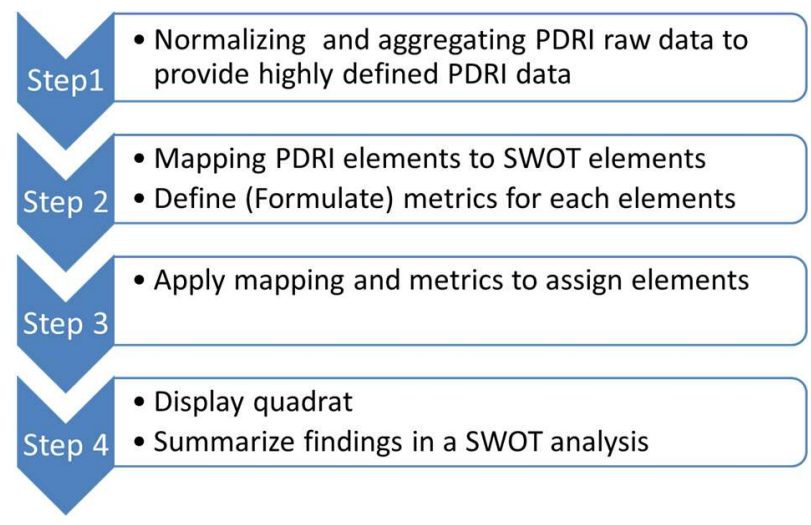

Fig. 5. Methodology steps

Step 1: As a widely adopted FEP standard, the PDRI facilitates project appraisal by stipulating key project elements that are rated by stakeholders in terms of scope definition. The PDRI scoring framework enables the project team to pool their expertise in a workshop format to identify and understand the influence of the crossfunctional risks in the project. The data collected during PDRI sessions provides an ideal structure to apply big data analytics allowing an analyst to mine historical PDRI data for constituent elements. Historically, PDRI data has been largely unstructured, and this research contains a large data set for this type of analysis. To overcome this challenge, PRDI data must be normalized based on specific analytical requirements.

Step 2: The pertinent factors of the external and internal environment are recognized and incorporated in the SWOT analysis. Using PDRI scores can help the project team uncover opportunities that they are well-positioned to exploit. By understanding the weaknesses of the project, the project management team can manage and eliminate threats that would otherwise catch them unawares. Hence, the PDRI elements should be categorized to SW and OT (consider an internal and external basis). Next, they should be classified to $\mathrm{S}, \mathrm{W}, \mathrm{O}$ and $\mathrm{T}$ based on their associated scores: (1) Strengths (good/inside); (2) Weaknesses (bad/inside); (3) Opportunities (good/outside); and (4) Threats (bad/outside).

To elaborate further on step 2, continuous appraisal of factors affecting project goals is necessary for instance, duration constraints in construction, predetermined 
monetary value, and quality levels so they can be addressed by the project manager. Both internal and external prospects need to be realized after defining the goals, for achieving the goals as well as challenges in attaining those goals. The project management team responds by analyzing the identified strengths, weaknesses, opportunities, and threats, as per the requirement. The team also extricates the key success factors that can affect the goals. The key or critical success factors can include management, organization, and organization of construction activities. They are often complex in nature. The relation of the physical environment, construction site conditions, and all stakeholders define the external domain for key success factors. These factors pose a bigger challenge due to the complexity of controlling them.

Lastly, there is a need to examine strengths, weaknesses, opportunities, and threats and find a process for eliminating the weaknesses and threats. For instance, SWOT analysis from a construction business's point of view will include certain elements of strengths, weaknesses, opportunities, and threats, which can be further described. Strengths include track records, resource availability, skillful work team, knowledge of the firm, use of modern technology and machinery, processes and systems, a good relationship with material suppliers, and so forth. Weaknesses can include gaps in knowledge, inexperienced workforce, resistance to new methods of working, lack of coordination, injury-prone working condition, the absence of processes, and systems. Opportunities include political influences, favorable contract terms, reliable investors, a booming economy, favorable financing arrangements, the prospects of getting future projects, changes in technology, market condition, and government policy widening the scope of work, and the likelihood of having a project team that is wellcoordinated. Threats often include a lack of adaptation to technological and infrastructural changes, changing customer behavior, new innovations from the competition, manipulation on the construction site, a supervisory board with a disinterest in the project, and frequent revisions in the space allocation.

Step 3: Assign a score for each feature and sort them accordingly. A high score means there is the greater importance of the previously selected element. In this step, the numerical values for the factors representing the strategic planning process are highlighted. There may be consideration of new goals and defined strategies for implementing them with respect to the foremost factors. The threshold of 1.25 and 3 have been determined with a consultation with PDRI experts (CII members). Any element with a score between those two points should be excluded from consideration.

Step 4: Display quadrat; the map of the critical issues gives one a clear idea of what needed to be addressed in the strategy. Therefore, it is acceptable to move onto the SWOT analysis to summarize the findings of the company and how it's currently prepared to address these noted critical issues.

\section{Data Collection and Process}

This study focused on organizations that have implemented PDRI is a standardized tool used across their capital project portfolios. In an effort to develop a truly objective and quantitative analysis method, we decided to rely on data rather than only comments from experts. To accomplish this, we will use extensive data from more than 70 industrial construction projects completed within North America. These projects furnish output in terms of electricity, chemical compounds, assemblies, and subassemblies. These projects have been performed and completed by CII members. The PDRI assessment team of these construction firms evaluated the level of the efforts for project definition during the front-end planning phase and determined their score or level of effort. In order to maintain secrecy, the real names of construction companies and the projects have not been disclosed. The PDRI for "Industrial" template offers a thorough checklist of three sections of the PDRI along with 15 categories, and 70 elements. Considering the available PDRI data for 70 sample projects, approximately 500 data points were analyzed as a large and varied data set. Table 3 presents a statistical summary such as the mean, standard deviation, standard error, and t-test of the data for most variables. Based on the results of the equal variance t-test, there is a significant mean difference at a $5 \%$ significance level. It is very obvious from Table 3 that all variables show statistically significant proof of mean different from zero (since $\mathrm{p}$-values $<0.05$ ).

Data has been also used to perform a sensitivity analysis to investigate strategic planning issues and acquire specific insights on the effect of missing input or output variables. Based on the analysis of variance (ANOVA) technique, there is statistically significant evidence to show a significant relationship between all the variables at the 0.05 level of significance ( $p$-value $=0.000<0.05$ ).

\section{Discussion and Analysis}

The SWOT analysis, as a result of the proposed approach, assists the project management team in identifying strengths and weaknesses early and enhance project scope definition completeness prior to procurement and project execution phases. The PDRI elements, as a result of SWOT analysis, performed on these 70 construction projects are summarized in Table 4. This result could be employed for analyzing the factors that influence the status of industrial construction projects with an eye to the future. The limitation to this research project derives from data collected, as these data may have been collected from the project from weeks, months, or even a year prior to the analysis.

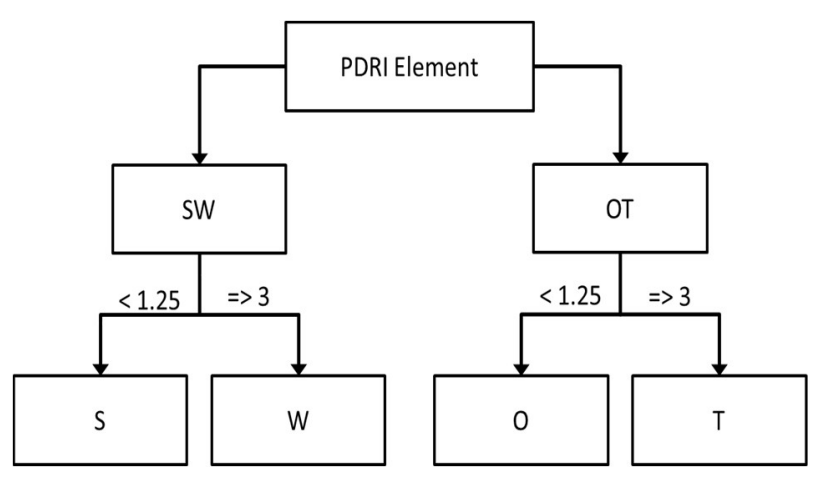

Fig. 6. Methodological decision tree, including internal factors (SW) - the strengths and weaknesses internal to the organization external factors (OT) - the opportunities and threats presented by the environment external to the organization 
Table 3. Statistical summary and comparison of means

\begin{tabular}{|c|c|c|c|c|c|}
\hline Variable & Mean & Std Dev & SE-Mean & T-test & p-value \\
\hline Reliability Philosophy & 1.525 & 0.953 & 0.124 & 12.29 & 0.000 \\
\hline Maintenance Philosophy & 1.831 & 0.968 & 0.126 & 14.53 & 0.000 \\
\hline Operating Philosophy & 1.458 & 1.088 & 0.142 & 10.29 & 0.000 \\
\hline Products Level & 0.237 & 0.568 & 0.0739 & 3.21 & 0.002 \\
\hline Market Strategy level & 1.424 & 0.894 & 0.116 & 12.23 & 0.000 \\
\hline Project Strategy & 1.559 & 0.772 & 0.100 & 15.52 & 0.000 \\
\hline Affordability & 1.915 & 0.857 & 0.112 & 17.17 & 0.000 \\
\hline Capacities - Level & 0.559 & 0.749 & 0.098 & 5.74 & 0.000 \\
\hline Future Expansion & 0.525 & 0.751 & 0.098 & 5.37 & 0.000 \\
\hline Expected Project & 1.220 & 0.697 & 0.090 & 13.46 & 0.000 \\
\hline Social Issues & 1.746 & 0.822 & 0.107 & 16.31 & 0.000 \\
\hline Technology Level & 1.475 & 0.774 & 0.101 & 14.64 & 0.000 \\
\hline Processes - Level & 0.864 & 1.042 & 0.136 & 6.38 & 0.000 \\
\hline Project Objectives & 1.763 & 0.858 & 0.112 & 15.78 & 0.000 \\
\hline Project Design $\mathrm{C}$ & 1.542 & 0.816 & 0.106 & 14.51 & 0.000 \\
\hline Site Characteristic & 1.593 & 1.100 & 0.143 & 11.12 & 0.000 \\
\hline Dismantling and Dem & 1.814 & 1.121 & 0.146 & 12.42 & 0.000 \\
\hline Lead/Discipline & 2.186 & 0.919 & 0.120 & 18.28 & 0.000 \\
\hline Project Schedule & 2.797 & 0.886 & 0.115 & 24.24 & 0.000 \\
\hline Process Simplification & 0.847 & 1.014 & 0.132 & 6.42 & 0.000 \\
\hline Design and Material & 1.356 & 0.760 & 0.099 & 13.70 & 0.000 \\
\hline Design for Construction & 2.237 & 1.135 & 0.148 & 15.14 & 0.000 \\
\hline Site Location - Level & 0.254 & 0.709 & 0.092 & 2.75 & 0.000 \\
\hline Surveys and Soil Test & 0.627 & 0.998 & 0.130 & 4.83 & 0.000 \\
\hline Environmental Asses & 1.627 & 1.113 & 0.145 & 11.23 & 0.000 \\
\hline Permit Requirements & 1.712 & 0.929 & 0.121 & 14.15 & 0.000 \\
\hline Utility Sources wit & 1.102 & 1.282 & 0.167 & 6.60 & 0.000 \\
\hline Fire Protection & 1.153 & 1.186 & 0.154 & 7.46 & 0.000 \\
\hline Process Flow Sheets & 0.695 & 1.163 & 0.151 & 4.59 & 0.000 \\
\hline Heat and Material Bal & 0.525 & 1.056 & 0.138 & 3.82 & 0.000 \\
\hline Piping and Instrument & 1.102 & 1.386 & 0.180 & 6.11 & 0.000 \\
\hline Process Safety Mana & 1.407 & 0.931 & 0.121 & 11.61 & 0.000 \\
\hline Utility Flow & 0.441 & 1.005 & 0.131 & 3.37 & 0.001 \\
\hline Specifications & 1.424 & 1.276 & 0.166 & 8.57 & 0.000 \\
\hline Piping System & 0.695 & 1.118 & 0.146 & 4.77 & 0.000 \\
\hline
\end{tabular}

Hence, this method may have led to some extent inaccurate information due to the evolution of construction technology and construction management methodologies. Another limitation could be the project selection process for this study, as they are chosen based on voluntary endeavor and not on a random sampling process. Since CII members firms could select projects with a bias toward successful projects. Thus, interviews have been conducted extensively to enhance communications, increase understanding, and identify critical issues.

The ordinal logistic regression technique is also used in this project. Using this technique provides the opportunity to analyze and determine if significant relationships existed between the response variables; and a set of independent variables such as the technological level, processes level, market strategy level, affordability, and capacities. One of the powerful statistical techniques is logistic regression (Hosmer and Lemeshow, 2000) which can be used in modeling the relationship of a categorical outcome and a set of independent variables.

Examples of these variables are gender and total household income. Unlike linear regression that predicts the actual values of the response variables, logistic regression models the probability associated with each level of the response variable by getting a linear relationship between predictor variables and a link function of these probabilities. Different link functions offer different levels of "goodness of fit" for the data. The goal of the logistic regression model is to discover the best fitting and most reasonable model to describe the relationship between the response variable and the set of the explanatory variables. The multiple logistic regression models can be written as:

$\ln ($ oddsratio $)=\beta_{0}+\beta_{1} X_{1 \mathrm{i}}+\beta_{2} X_{2 \mathrm{i}}+\ldots+\beta_{\mathrm{k}} \mathrm{X}_{\mathrm{ki}}+\varepsilon_{\mathrm{i}}$ 
Table 4. A result of SWOT analysis

\begin{tabular}{|c|c|}
\hline STRENGTH & WEAKNESS \\
\hline B1. Products & P3. Shut Down/Turn- \\
\hline B5. Capacities & Around \\
\hline B6. Future Expansion & Requirements \\
\hline Considerations & P4. Pre-Commission \\
\hline $\begin{array}{l}\text { B7. Expected Project Life } \\
\text { Cycle }\end{array}$ & $\begin{array}{l}\text { Turnover Sequence } \\
\text { Requirements }\end{array}$ \\
\hline E1. Process Simplification & P5. Startup \\
\hline F2. Surveys and Soil Tests & Requirements \\
\hline $\begin{array}{l}\text { G2. Heat and Material } \\
\text { Balances }\end{array}$ & \\
\hline G5. Utility Flow Diagrams & \\
\hline G12. Piping Specialty Items & \\
\hline List & \\
\hline $\begin{array}{ll}\text { I2. } & \begin{array}{l}\text { Architectural } \\
\text { Requirements }\end{array}\end{array}$ & \\
\hline $\begin{array}{l}\text { J1. Water Treatment } \\
\text { Requirements }\end{array}$ & \\
\hline K3. Electrical Area & \\
\hline $\begin{array}{l}\text { M1. CADD/Model } \\
\text { Requirements }\end{array}$ & \\
\hline THREAT & OPPORTUNITY \\
\hline N3. Risk Analysis & B2. Market Strategy \\
\hline D6. Project Schedule & $\begin{array}{l}\text { B4. Affordability/ } \\
\text { Feasibility } \\
\text { B8. Social Issues } \\
\text { F1. Site Location } \\
\text { F3. Environmental } \\
\text { Assessment } \\
\text { F4. Permit } \\
\text { Requirements }\end{array}$ \\
\hline
\end{tabular}

In Eq. (1), $\mathrm{K}$ denotes the number of independent variables in the model and represents the random error in an observation i. Logistic regression is based on the odds ratio, which represents the probability of success compared with the probability of failure. The maximum likelihood technique is used to obtain the estimates of the parameters in the logistic regression Eq. (1). The deviance can be used as a statistic to assess the model's goodness of fit. The model is generally considered reasonable if the deviance is not significantly large.

Table 5 presents the ordinal logistic regression results for this study. Due to space limitations in the table, only some of the significant explanatory variables are included. As one can see, several important variables are significant at the 0.05 level for the logistic regression model such as the technology level, expected project life cycle, and project design criteria.

As can be seen from the logistic regression results, several important variables are significant at the 0.05 level for the logistic regression model such as the technology level, expected project life cycle, site location level, piping system requirement, and project design criteria since $\mathrm{p}$ values are less than 0.05 . at least one coefficient is different from zero, once testing that all the coefficients associated with predictors equivalent to zero. There is statistically sufficient evidence to construe that at least one of the estimated coefficients is dissimilar zero since $(G=145.731$ with a p-value of 0.000$)$. Using the deviance to evaluate the righteousness of fit for the entire model, if the p-value is lesser than the significance, the test rejects the null hypothesis. In this case, the model fits the data sufficiently. Since the p-value for the deviance test is 0.987 , this demonstrates there is no evidence to claim that the model does not fit the data adequately. For further study, the authors suggest targeting a larger sample size and use other statistical methods such as factor analysis and chi-square test.

The result of this study for capital construction projects is an early diagnostic tool level. The developed tool can set apart misalignments, barriers, and bottlenecks. It could also obstruct the efficient transfer of the project resources. It also lets the key project experts promptly recognize project risk factors associated with the defined outcomes for cost, schedule, and operating performance. Most importantly, it can be used to assess the completeness of scope definition at any point before the detailed design phase of the construction project. The proposed analytical approach can also be undertaken to provide a comprehensive perception of the recent state of PDRI, and key strategies to achieve the stated objectives. When construction key construction firms are dealing with hundreds of projects each year, PDRI big data analysis has the potential to deliver the necessary intelligence and level of detail to facilitate a portfolio manager's decision-making process. With PDRI big data analysis, portfolio managers can have a more cognitive judgment of which portfolio features require greater prioritization. The value of the portfolio can be maximized by ensuring an exhaustive set of information about FEP during the portfolio design and management phase. Types of analysis that can be applied to historical PDRI data include FEP elements having the greatest impact on project performance; leading indicators for forecasting project performance in terms of cost and time overrun; insights into project status using key performance indicators; projects classification based on major associated risks; and understanding FEP issues (low scored elements). These deliverables can also support continuous improvement in the FEP phase. During the course of this study, several areas have been determined as potential areas for improvement and future studies, which include: (1) understand PDRIs most influential factors on cost and schedule; (2) track low definition elements by portfolio; (3) identify continuous improvement opportunities in front-end planning.

\section{Conclusions}

The suitability of SWOT components and the possibilities for its further application, by using real-world project data, in different situations are discussed. This study also examines the potential advantages and intrinsic values of SWOT during FEP phases to provide the potential implications of these results as they may or may not contribute to a project's success. The results also provide an opportunity to explicitly understand the many possible determinants of effectiveness in the context of planning.

Applying the PDRI methodology, key project stakeholders and team members can arrest mitigation action items. The PDRI is beneficial and advantageous to prompts the owner and design team to perform an initial validation of their business and design assumptions compared to jurisdictional necessities and the public expectations. This valuation should be conducted in the early stage of the project. The results of the study have shown that PDRI-Infrastructure can efficiently be applied to advance the expectedness of project outcomes. 
Table 5. Logistic regression results

\begin{tabular}{lcccc}
\hline \multicolumn{1}{c}{ Variable } & Coefficient & SE Coefficient & Z-test & p-value \\
\hline Expected Project Life Cycle & -3.388 & 1.326 & -2.55 & $0.011^{*}$ \\
Social Issues - Level & 3.879 & 2.212 & 1.75 & 0.079 \\
Technology - Level & -5.581 & 2.449 & -2.28 & $0.023^{*}$ \\
Project Objectives Statement & -3.171 & 2.212 & -1.66 & 0.097 \\
Project Design Criteria & 4.029 & 1.872 & 2.15 & $0.031^{*}$ \\
Design and Material Alternate & -4.498 & 2.028 & -2.22 & $0.027^{*}$ \\
Design for Constructability & 3.734 & 1.76 & 2.12 & $0.034^{*}$ \\
Site Location - Level & 4.619 & 2.204 & 2.1 & $0.036^{*}$ \\
Utility Sources with Supply & -1.284 & 0.763 & -1.68 & 0.092 \\
Piping System Requirements & -1.602 & 0.63 & -2.54 & $0.011^{*}$ \\
Plot Plan - Level & 0.637 & 0.386 & 1.65 & 0.099 \\
Equipment Location Drawing & 1.297 & 0.683 & 1.9 & 0.058 \\
Equipment Utility Requirements & -1.569 & 0.701 & -2.24 & $0.025^{*}$ \\
Civil/Structural Requirements & -0.599 & 0.304 & -1.97 & $0.049^{*}$ \\
Instrument and Electrical Specs & 0.837 & 0.421 & 1.99 & $0.047^{*}$ \\
Eng./Construction & 1.546 & 0.674 & 2.29 & $0.022^{*}$ \\
Training Requirements & -0.969 & 0.568 & -1.71 & 0.088 \\
\hline
\end{tabular}

Nevertheless, the use of PDRI (Infrastructure) alone could not confirm the success of projects. Once it is combined with an intact and sound planning process, SWOT analysis, team alignment, and effective execution, it has the potential to advance and improve the likelihood of meeting/exceeding project goals and objectives. The contribution of this study to the existing body of knowledge is to apply the data from 70 actual capital industrial projects from the same industry segment as a means of strengths, weaknesses, opportunities, and threats (SWOT) for evaluating the entire FEP process by using PDRI methodology. However, the method proposed here can be made more broadly applicable to further development, such as applications in operational excellence management - where health and safety risk reporting is a constant challenge for capital projects and owners.

\section{References}

Allport, R., Brown, R., Glaister, S., and Travers, T. (2008) Success and failure in urban transport infrastructure projects. KPMG Intternational.

Banihashemi, S., Hosseini, M. R., Golizadeh, H., and Sankaran, S. (2017). Critical success factors (CSFs) for integration of sustainability into construction project management practices in developing countries. International Journal of Project Management, 35(6), 1103-1119.

Bresnen, M. (2007). Deconstructing partnering in projectbased organisation: Seven pillars, seven paradoxes, and seven deadly sins. International Journal of Project Management, 25(4), 365-374.

Chan, A. P., Scott, D., and Lam, E. W. (2002). Framework of success criteria for design/build projects. Journal of Management in Engineering, 18(3), 120-128.

Cho, C. S. and Gibson Jr., G. E. (2001). Building project scope definition using project definition rating index. Journal of Architectural Engineering, 7(4), 115-125.
Collins, A. and Baccarini, D. (2004). Project Success - A Survey. Journal of Construction Research, 5(2), 211231.

Construction Industry Institute (CII). (2010). Project definition rating index for infrastructure projects. Implementation Resource 268-2, First Edition, Austin, TX.

Cox, A. and Ireland, P. (2006). Relationship management theories and tools in project procurement. In $S$. Prykeand H. Smyth (Eds.), The management of complex projects: A relationship approach (pp. 251281).

David, M. E., David, F. R., and David, F. R. (2017). The quantitative strategic planning matrix: a new marketing tool. Journal of Strategic Marketing, 25(4), 342-352.

dos Santos, R. B. and Jungles, A. E. (2016). Risk level assessment in construction projects using the schedule performance index. Journal of Construction Engineering, 2016, 1-8.

Eastman, C., Teicholz, P., Sacks, R., and Liston, K. (2011). BIM handbook: A guide to building information modeling for owners, managers, designers, engineers, and contractors (2nd ed.). Wiley. Hoboken, $\mathrm{NJ}$ :

Eskerod, P., Huemann, M., and Ringhofer, C. (2015) Stakeholder inclusiveness: Enriching project management with general stakeholder theory. Project Management Journal, 46(6), 42-53.

Ezeldin, A. S. and Sharara, L. M. (2006). Neural networks for estimating the productivity of concreting activities. Journal of Construction Engineering and Management, 132(6), 650-656.

Flyvberg, B. (2014). What you should know about megaprojects and why: An overview. Project Management Journal, 45(2), 6-19.

Gemünden, H. G. (2015). Success factors of global new product development programs, the definition of project success, knowledge sharing, and special issues of Project Management Journal $\AA$. Project Management Journal, 46(1), 2-11. 
Gerwin, D. and Susman, G. (1996). Special issue on concurrent engineering. IEEE Transactions on Engineering Management, 43(2), 118-123.

Gibson, E. and Dumont, P. (2004). RR113-11 - Project Definition Rating Index (PDRI) for industrial projects. Research Report, CII Publications, and Events Center, Construction Industry Institute. Austin, TX.

Gibson, G. E. (2005). Alignment during pre-project planning: a key to project success: implementation resource 113-3. Construction Industry Institute. Austin, TX.

Gibson, G. E., Irons, K. T., and Ray, P. E. (2006). Front end planning for buildings. Architectural Engineering Conference (AEI), ASCE Library.

Gibson, G. E., Bingham, E., and Stogner, C. (2010). Front end planning for infrastructure projects. In Proceedings of Construction Research Congress 2010, ASCE, May 08-11, 2010, Banff, Alberta, pp. 1125-1135.

Gupta, P. (2004). Six sigma business scorecard: ensuring performance for profit. McGraw-Hill. New York.

Helm, J. and Remington, K. (2005). Effective project sponsorship: An evaluation of the role of the executive sponsor in complex infrastructure projects by senior project managers. Project Management Journal, 36(3), 51-61.

Hill, T. and Westbrook, R. (1997). SWOT analysis: it's time for a product recall. Long range planning, 30(1), 46-52.

Hosmer, D. and Lemeshow, S. (2000). Applied Logistic Regression, 2nd Edition. Wiley-Interscience; John Wiley and Sons. New York.

Johnson, F., Leenders, M. R., and Flynn, A. E. (2021). Purchasing and supply management. McGraw-Hill Companies, Inc.

Kerzner, H. (2018). Project management best practices: achieving global excellence. Wiley. New York.

Koulinas, G. K., Xanthopoulos, A. S., Tsilipiras, T. T., and Koulouriotis, D. E. (2020). Schedule delay risk analysis in construction projects with a simulationbased expert system. Buildings, 10(8), 134.

Lee, L., Reinicke, B., Sarkar, R., and Anderson, R. (2015). Learning through interactions: improving project management through communities of practice. Project Management Journal, 46(1), 40-52.

$\mathrm{Lu}$, W. (2010). Improved SWOT approach for conducting strategic planning in the construction industry. Journal of Construction Engineering and Management, 136(12), 1317-1328.

Lu, W., Ye, K., Flanagan, R., and Jewell, C. (2013). Developing construction professional services in the international market: SWOT analysis of China. Journal of Management in Engineering, 29(3), 302-313.

Luu, T. V., Kim, S. Y., Cao, H. L., and Park, Y. M. (2008). Performance measurement of construction firms in developing countries. Construction Management and Economics, 26(4), 373-386.

Machiels, T., Compernolle, T., and Coppens, T. (2021). Real option applications in megaproject planning: trends, relevance and research gaps. A literature review. European planning studies, 29(3), 446-467.

Miller, R. and Hobbs, B. (2005). Governance regimes for large complex projects. Project Management Journal, 36(3), 42-50.

Mirza, N. M., Pourzolfaghar, Z., and Shahnazari, M. (2013). Significance of scope in success of project. Procedia Technology, 9, 722-729.
Morris, P. (2013). Reconstructing project management reprised: A knowledge perspective. Project Management Journal, 44(5), 6-23.

Oppong, G. D., Chan, A. P., and Dansoh, A. (2017). A review of stakeholder management performance attributes in construction projects. International journal of project management, 35(6), 1037-1051.

Park, H., Thomas, S., and Tucker, R. (2005). Benchmarking of construction productivity. Journal of Construction Engineering Management, 131(7), 772778.

Project Management Institute (PMI). (2013). A guide to the project management body of knowledge $(\mathrm{PMBOK} \AA$ guide $)$ — Fifth edition. Author. Newtown Square, PA.

Rankin, J., Fayek, A. R., Meade, G., Haas, C., and Manseau, A. (2008). Initial metrics and pilot program results for measuring the performance of the Canadian construction industry. Canadian Journal of Civil Engineering, 2008, 35(9): 894-907.

Rolfe, B., Segal, S., and Cicmil, S. (2016). An existential hermeneutic philosophical approach to project managing. Project Management Journal, 47(3), 48-62.

Safa, M. (2013). An advanced construction supply nexus model. Ph.D. thesis, University of Waterloo, ON, Canada.

Safa, M., Sabet, A., MacGillivray, S., Davidson, M., Kaczmarczyk, K., Gibson, G. E., and Haas, C. (2015). Classification of Construction Projects. International Journal of Civil, Environmental, Structural, Construction, and Architectural Engineering, 9(6), 625-633.

Safa, M., Haas, C. T., Hipel, K. W., and Gray, J. (2013). Front End Planning Tool (FEPT) based on electronic process management. Journal of Construction Engineering and Project Management, 3(2), 1-12.

Safa, M., Sabet, A., Ghahremani, K., Haas, C., and Walbridge, S. (2015a). Rail corrosion forensics using 3D imaging and finite element analysis. International Journal of Rail Transportation, 3(3), 164-178.

Safa, M., Shahi, A., Haas, C. T., Fiander-McCann, D., Safa, M., Hipel, K., and MacGillivray, S. (2015b). Competitive intelligence (CI) for evaluation of construction contractors. Automation in Construction, 59, 149-157.

Serrador, P. and Turner, R. (2015). The relationship between project success and project efficiency. Project Management Journal, 46(1), 30-39.

Shahi, A., Safa, M., Haas, C. T., and West, J. S. (2014). Data fusion process management for automated construction progress estimation. Journal of Computing in Civil Engineering, 29(6), 04014098.

Shokri, S., Safa, M., Haas, C. T., and Haas, R. C. G. (2011). A conceptual framework to improve information and process management in the execution of capital projects. In 3rd International/9th Construction Specialty Conference (pp. 14-17).

Stewart, R. A., Mohamed, S., and Daet, R. (2002). Strategic implementation of IT/IS projects in construction: a case study. Automation in construction, 11(6), 681-694.

Sutterfield, J. S., Friday-Stroud, S. S., and ShiversBlackwell, S. L. (2006). A case study of project and stakeholder management failures: Lessons learned. Project Management Journal, 37(5), 26-35.

Teixeira, F. Cordeiro, M. N. D. S. (2017). Strengths, weaknesses, opportunities, and threats: computational 
studies of $\mathrm{Mn}$ - and Fe-catalyzed epoxidations. Catalysts, 7(1), 2.

Turner, R. and Zolin, R. (2012). Forecasting success on large projects: developing reliable scales to predict multiple perspectives by multiple stakeholders over multiple time frames. Project Management Journal, 43(5), 87-99.

Walker, A. (2015). Project management in construction. John Wiley and Sons.

Ward, J. A. (1995). Project pitfalls. Information System Management, 12(1). 74-76.

Weeks, K., Safa, M., Kenyon, G., and Levius, S. (2020). Offshore multi-purpose platform efficacy by US coastal areas. Renewable Energy, 152, 1451-1464.

Weerasinghe, G., Soundararajan, K., and Ruwanpura, J. (2007). LEED-PDRI framework for pre-project planning of sustainable building projects. Journal of Green Building, 2(3), 123-143.

Willis, C. J. and Rankin, J. H. (2012). Demonstrating a linkage between construction industry maturity and performance: a case study of Guyana and New Brunswick. Canadian Journal of Civil Engineering, 39(5), 565-578.

Yuan, H. (2013). A SWOT analysis of successful construction waste management. Journal of Cleaner Production, 39, 1-8.

Yüksel, İ. and Dagdeviren, M. (2007). Using the analytic network process (ANP) in a SWOT analysis-A case study for a textile firm. Information Sciences, 177(16), 3364-3382.

Zavadskas, E. K., Turskis, Z., and Tamosaitiene, J. (2011). Selection of construction enterprises management strategy based on the SWOT and multi-criteria analysis. Archives of civil and mechanical engineering, 11(4), 1063-1082.

Zheng, X., Le, Y., Chan, A. P., Hu, Y., and Li, Y. (2016). Review of the application of social network analysis (SNA) in construction project management research. International Journal of Project Management, 34(7), 1214-1225.

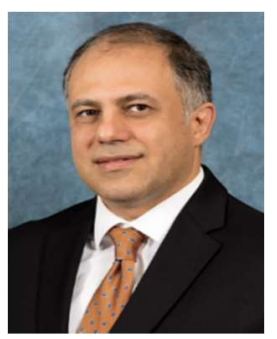

Dr. Mahdi Safa is a Senior Lecturer at the University of Houston, pursuing research on the design and optimization of supply chain processes, maritime/coastal/port construction, modeling and simulation, energy systems, and integration of new technologies in the megaproject. He has $15+$ years of broad management experience, specializing in planning, budgeting, organizing, and controlling resources, procedures, and protocols. Dr. Safa has a unique combination of engineering and business development expertise by focusing on Ph.D. and Masters in Construction Management, Industrial Engineering, and Business Administration. He has received several research and teaching awards and has numerous publications.

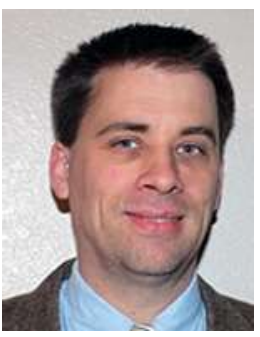

Dr. Weeks is an Associate Professor of Management at Lamar University. $\mathrm{He}$ is a member of INFORMS and POMS among other organizations. Dr. Weeks has written numerous grant proposals and authored many journal publications, including venues such as Renewable Energy, International Journal of Production Research, and International Journal of Productivity and Performance Management. Dr. Weeks' research interest lies in the topics of improving operational efficiency and performance. This has led to work on areas involving green supply chain, manufacturing, and port analyses.

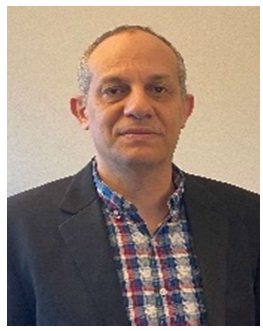

Dr. ELHoubi is a Professor at the Information Systems and Analysis Department, College of Business at Lamar University, Beaumont, Texas. He has a Ph.D. in Statistics from the University of Wyoming and a master's degree from Iowa State University and Kansas State University in Statistics. He has over seventeen years of teaching experience and has published several papers. His research areas of interest are in Applied Statistics, Biostatistics, Mixed Models, Time Series, multiple regression, and Logistic Regression.

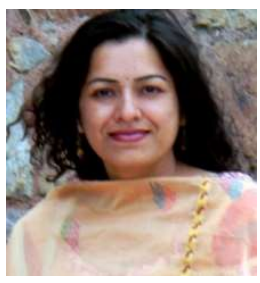

Dr. Nomita Sharma is a faculty of Applied Social Science and Humanities at the University of Delhi, India. Her research interests include Management of Innovation, barriers to innovation, sectoral innovation, project management, innovation in the construction sector, small and medium enterprises, supply chain.

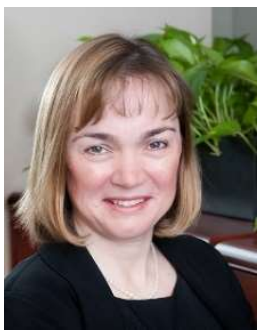

Sandra MacGillivray is the Managing Director for Valency Inc., an implementer of best practices from the Construction Industry Institute (CII) that dramatically improve capital project performance. She is a Certified PDRI Facilitator, Registered Education Provider (REP) with the Construction Industry Institute (CII), a Project Management Professional (PMP), and a PMI Risk Management Professional (PMI-RMP) with over 15 years of project management experience. Sandra is a past research team member with the Construction Industry Institute on front-end planning, risk management, and portfolio management. She holds a Bachelor of Science from the University of Waterloo and a Master in Business Administration from Wilfrid Laurier University. 